\title{
A comparison of motor vehicle recalls between Brazil and Germany: different approaches and results
}

\author{
Gabriel Erwin Gruber ${ }^{1}$, Paulo Carlos Kaminski ${ }^{1}$, Emilio Carlos Baraldi1* \\ ${ }^{1}$ Departamento de Engenharia Mecânica, Escola Politécnica, Universidade de São Paulo - USP
}

\begin{abstract}
Failures during the product development process can lead to problems in product quality and reliability, which in turn can cause serious harm to its end-users. When such failures are discovered after a vehicle is already in usage, a safety recall is required, which can incur in potential damage and losses to brand image. Recall rates of multinational companies can be affected by regional law enforcement and quality requirements of local governments. Despite its importance for the safety of end-users, the automotive vehicle recall process in Brazil is little studied by the academy. The main objective of this project was to collect data and clarify how the automotive vehicle recall process is carried out in Brazil and how it could be improved by comparing it with Germany, a country with very advanced regulations in this sector and with a fleet of vehicles similar to that of Brazil. To achieve this goal, the work provided an overview of the available data in both countries, developed a scalable method for comparing recall rates and an analysis of recall rates of the main OEMs in operation. The work concludes using this data to draw insights on how these processes can be improved.
\end{abstract}

Keywords: recall, automotive industry, product development process.

\section{Introduction}

During the product development process, failures in the company's internal quality assurance during the product design process can lead to serious hazards to the user of such products. In the motor vehicles industry, a defective product can cause hazards such as burnings, lacerations and catastrophic accidents, potentially injuring several victims.

The International Organization of Motor Vehicle Manufacturers (OICA) estimates that there are currently more than 1282 million vehicles in use worldwide (International Organization of Motor Vehicle Manufacturers, 2018). Because of its size and the number of people it affects, this industry is a special focus for these types of problems. When such a failure is discovered after the vehicle is already in the market, a safety recall is required, which may incur in potential damage to the car-maker image and could cause severe financial losses (Giakatis \& Rooney, 2000; Bernon et al., 2018). A recall can be initiated voluntarily by the company itself or requested directly by a government, according to local laws (Rupp \& Taylor, 2002).

Recall rates of multinational companies therefore can be affected by local quality requirements as well as by regional laws in place, for imported vehicles. For this reason, a comparison of how recalls are handled in different countries provides meaningful insights on how different governmental strategies affect recalls. In this research, Brazil and Germany are taken into consideration because these countries have a similar fleet of vehicles in use (around 42 million and 48 million respectively) and similar number of licensed cars each year (Associação Nacional dos Fabricantes de Veículos Automotores, 2018; International Organization of Motor Vehicle Manufacturers, 2018). Aside from these quantitative similarities, these countries have very different governmental institutions for regulating recall actions with Germany being the home to several Original Equipment Manufacturers (OEMs) and Brazil still a developing country.

This research has an exploratory nature and its main objective is to gather data and shed more light on how the recall process towards automotive vehicles is conducted in Brazil and whether it can undergo any type of improvement. This will be accomplished by performing a secondary survey to collect information on how the recall process is carried out in Brazil and, once obtained this information, compare it with a similar type of information obtained from Germany - considered one of the largest and most efficient automotive industries in the world. This analysis will allow also the suggestion of improvements and even new research opportunities to advance this topic in Brazil. To do so, section 2 presents a literature review in the topics of product development

Received: 22, May 2020. Accepted: 28, Dec. 2020

*Corresponding author: Emilio C. Baraldi. E-mail: emiliobaraldi@yahoo.com.br 
process and recalls. Next, the methodology required for the acquisition of data and analyses are presented in section 3. Finally, the obtained results are shown in section 4 and the conclusions are drawn in section 5.

\section{State of the research}

This chapter presents the background theory surrounding the work and the gaps that were identified. Firstly, the subject of product development process is briefly introduced, focusing on the automotive sector and in possible problems that could arise during these types of processes. Next, the concept of product recall is presented as well as its consequences to the responsible manufacturer.

\subsection{Product development process}

Product development is defined by Krishnan \& Ulrich (2001) as "the transformation of a market opportunity and a set of assumptions about product technology into a product available for sale". The development of a new product with success incurs in attracting new customers, thus increasing the manufacturer's market share, besides reducing production costs and improving quality when compared to previous products (Clark \& Fujimoto, 1991; Lin \& Lu, 2006).

Krishnan \& Ulrich (2001) made a broad review of the research in Product Development Process (PDP), encompassing the academic fields of marketing, operations management and engineering design. Wynn \& Clarkson (2018) did an in-depth literature review of PDP and further classified and related the different existing approaches. One of the classifications done by these authors divided the existing models into: procedural models, analytical models, abstract models and management science/operations research models. In this article we focus on PDP approaches that classify as procedural models, which are defined as the ones that convey best practices intended to guide real-world situations.

Another possible classification of the different approaches for PDP is defined by Suh (2001) in the work where the concept of axiomatic design is introduced, with the goal to establish a scientific basis for the design area to optimize this process. Its classification encompasses four domains: customer, functional, physical and process.

Throughout the years, the procedural models for PDP have had several revolutions and changes in its paradigms and approaches. Table 1 shows the evolution of these different PDP approaches in chronological order, intended as a summary of the most important literature in the field, with the lines that involve the automotive sector in gray. Next, the authors and works shown in this table are introduced.

Table 1. Product Development Process (PDP) approaches.

\begin{tabular}{|c|c|c|c|}
\hline Author (s) & Year & Title & PDP approach \\
\hline Evans & 1959 & Basic design concepts & Design spiral \\
\hline Asimow & 1962 & Introduction to design & Production and consumption cycle \\
\hline VDI 2221 & $\begin{array}{c}1993 \\
\left(1986^{1}\right)\end{array}$ & $\begin{array}{l}\text { A systematic approach to the design of technical } \\
\text { systems }\end{array}$ & Guidelines to PDP phases and results \\
\hline Cooper & 1990 & State-gate systems: a new tool for managing & Stage gate systems \\
\hline Clark and Fujimoto & 1991 & $\begin{array}{l}\text { Product development performance: strategy, } \\
\text { organization and management in the world auto } \\
\text { industry }\end{array}$ & $\begin{array}{l}\text { Product development as a simulation of } \\
\text { consumer experience and an information } \\
\text { asset map of the product development }\end{array}$ \\
\hline Dieter and Schmidt & $\begin{array}{c}2009 \\
\left(1983^{1}\right)\end{array}$ & Engineering design & $\begin{array}{c}\text { The product development process in the point } \\
\text { of view of a mechanical engineer }\end{array}$ \\
\hline Clark and Wheelright & 1993 & Managing new product and process development & Development of funnel concept \\
\hline Ulrich and Eppinger & $\begin{array}{c}2012 \\
\left(2000^{1}\right)\end{array}$ & Product design and development & Generic model with six phases \\
\hline $\begin{array}{l}\text { Cooper, Edgettand } \\
\text { Kleinschmidt }\end{array}$ & 2001 & Portfolio management for new products & $\begin{array}{l}\text { Step-by-step framework to manage product } \\
\text { portfolios }\end{array}$ \\
\hline Weber & 2009 & Automotive development process & $\begin{array}{l}\text { Processes for successful customer-oriented } \\
\text { vehicle development }\end{array}$ \\
\hline Silva and Kaminski & 2015 & $\begin{array}{l}\text { Selection of virtual and physical prototypes in the } \\
\text { product development process }\end{array}$ & $\begin{array}{l}\text { Guidelines to select virtual and physical } \\
\text { prototypes in PDP and case study in } \\
\text { automotive sector }\end{array}$ \\
\hline Silva and Kaminski & 2017 & $\begin{array}{l}\text { Proposal of framework to managing the } \\
\text { automotive product development process }\end{array}$ & $\begin{array}{l}\text { Proposes a PDP framework for the } \\
\text { automotive sector. }\end{array}$ \\
\hline Baraldi and Kaminski & 2018 & $\begin{array}{l}\text { Reference model for the implementation of new } \\
\text { assembly processes in the automotive sector }\end{array}$ & $\begin{array}{l}\text { Guidelines for process development of new } \\
\text { assembly processes }\end{array}$ \\
\hline
\end{tabular}

${ }^{1}$ Year of first edition when the concept is introduced. Source: Adapted from Silva \& Kaminski (2017) and Baraldi \& Kaminski (2018). 
The basic design concepts of PDP were introduced by Evans (1959). The author laid out for the first time the framework of a design spiral, which is an interactive process where the process, and therefore the product, go through the different tasks in the spiral, making the product more detailed in each step, focusing on obtaining a final version that meets the project requirements.

Asimow (1962) in turn showed PDP in a more linear fashion. The author defends that during product development, four phases of its life cycle should be considered, namely: production, distribution, consumption and recovery. The design of a new product has been placed by the Association of German Engineers (VDI) in the guideline VDI 2221 as a core part of a products life cycle (VDI-Fachbereich Produktentwicklung und Mechatronik, 1993). This guideline defines generally valid principles for the design a new product independently of a specific branch of industry, showing specific phases and their necessary results so that the PDP can be successful.

Cooper (1990) also divided the PDP into similar phases or stages, but for him each of these phases should end with a gate, developing the stage-gate system. The goal of the gate is to verify that the deliverable results meet the necessary requirements, allowing the development to progress into further phases, thus focusing the work on process management.

Clark \& Fujimoto (1991) are the first identified authors to develop guidelines specifically for the automobile industry. In this work, product development is presented as a simulation of consumer experience, thus being classified in the customer domain. The authors also present an information asset map of the product development where information is shared through different phases of the PDP.

Dieter \& Schmidt (2009) intend to provide a realistic understanding of the engineering design process. The book presents different phases of the PDP and different types of design, in the point of view of engineers.

Clark \& Wheelwright (1993) present the concepts of effective organization and management of the product and process development. In this work, the authors developed the funnel concept that illustrates how companies select the most promising ideas for further development, focusing resources to make the best products reach the market.

The perspective of marketing, design and manufacturing were blended into a single approach for product development by Ulrich \& Eppinger (2012), for the first time in 2000, in the first edition of the book. It provides a set of product development methods that can be put directly into practice and includes key business function phases.

Cooper et al. (2001) presented a step-by-step framework to provide managers with new strategies to assess and realign their current research and development resource allocation, by correctly managing their product portfolio in an analogous manner to a financial portfolio, investing for maximum long-term growth. An important resource allocation during research and development is the selection of prototypes. Silva \& Kaminski (2016) developed guidelines to help companies select the best technique to create virtual and physical prototypes during PDP.

Focusing on the automotive process development, Weber (2009) presents a customer-oriented point of view on the PDP. Further, Silva \& Kaminski (2017), also focusing on automotive PDP, propose a complete framework to manage the automotive product development. It includes a reference model with the macro-phases of the process and technical and management gates (based in the stage-gate system) to be established. Finally, in the automotive sector, Baraldi \& Kaminski (2018) developed guidelines for process development of new assembly processes, describing its required tasks, quality checks, actions and validations.

These different approaches to PDP define the possible classifications and methods for solving the product development problem. Most of the approaches have a clear division of the phases of PDP between the development of the product and the production process. Most approaches also assume that this development can or should be iterative, refining the characteristics of the product and correcting possible problems throughout the development. Now that the different approaches to PDP are defined, it is possible to investigate the consequences of failures in specific phases, most notoriously during the product usage.

\subsection{Recalls}

During the product life cycle, the amount of resources spent in it is known to increase as it advances. Dieter $\&$ Schmidt (2009) have shown that most of products` costs are happen during the conceptual design of a product. Changing important features of the product at a late stage, when most of the costs have already been incurred, may increase the final cost of the product. It also allows to conclude that when failures are discovered further down the design process, repairing such failures will incur in higher costs.

This highlights the importance of a robust quality assurance police in the company, so that if a failure occurs it is found quickly, without affecting later parts of the product development process, so that the product can achieve higher profitability. 
Failures in the company's internal quality assurance during product's design will sometimes only be discovered during product use, in which case, if they pose a safety hazard for the users or if they don't deliver the advertised efficiency, a recall is required.

Evidence from different industry branches show various impacts of such failures in each sector. Hora et al. (2011) have studied the toy industry, looking into the time companies take to recall a product, analysing the role of recall strategy, product defect type and supply chain players influence. In the pharmaceutical industry, Ball et al. (2018b) have examined how competition influences product recalls, finding that it positively affects manufacturing-related recalls. Ball et al. (2018a), studying the medical device industry, identified a set of factors that influence recall decisions, such as the perceived patient harm potential and cost of the recall.

On the motor vehicles industry, because of its considerable market size, when such a failure occurs in a motor vehicle, possible resulting accidents can take the lives of many. According to the International Organization of Motor Vehicle Manufacturers (2018), there are more than 48 million vehicles currently in use in Germany and more than 42 million vehicles currently in use in Brazil. A recall in a popular vehicle brand may affect thousands or even millions of people in these countries.

When a car manufacturers or local law enforcement perceive safety hazards within their vehicles, a safety recall occurs. Car makers will try to identify and notify all affected vehicles and have the faults corrected at no cost to the owners. Vehicle safety recalls are carried out in an attempt to protect the users and the general public (Bates et al., 2007).

A recall incurs in direct costs to the OEM, such as the cost of advertisement, logistics and replacement parts. A comprehensive study made by Bernon et al. (2018) shows that recalls also bring about significant damages to the brand name and therefore to stock values and shareholder wealth. For this reason, recalls are highly undesirable for car makers.

Companies may therefore attempt to perform a silent recall (where parts are switched out during regular maintenance of the product) or even avoid recalling a product whatsoever, if they think the damage and the costs that would arise from the cars failing are smaller than the damage and costs of a recall action.

For this reason, each government must regulate and oversee recall actions, to keep its population safe and informed from possible hidden (deliberately or not) hazards.

Rupp \& Taylor (2002) discuss who is responsible for and who actually initiates a recall in an analysis on the USA. The work reaches the conclusion that the American government is more likely to initiate larger, less hazardous recalls involving older models with customer reported injuries, whereas firms conduct recalls when the benefits (reduced expected liability) exceed the costs of repairs. This logic can be derived to other countries as well, because the larger and more hazardous recalls are, the more likely they are to negatively affect the brand image of manufacturers, and therefore OEMs are more inclined to act in these cases.

An additional discussion on government activities in recall actions is done by Cavazos et al. (2018). In this work, data from automotive recall actions in the USA from 1966 to 2010 is examined. It reveals that "increases in government surveillance are associated with firms going beyond what is legally required of them by initiating voluntary product recalls for defects not covered in existing government regulation". Thus, government actions influence not only government-initiated recall actions but also voluntary recalls.

Recalls should then vary from country to country depending on how local government does surveillance, and some recall actions will vary depending on what the legislation considers hazardous or not. A comparison between countries could reveal these differences and bring light to their possible causes.

Baraldi \& Kaminski (2016) make a comprehensive investigation of the causes for recalls in automotive vehicles marketed in Brazil. The work gives important insight on the differences between recalls caused by failures in the product design and those caused by failures in the process. Further work on the topic could identify trends and compare the results to the rates in countries that have the more important OEM headquarters.

In this context, a gap in the state of the research is that no recent researches have done a comparison of recall actions in different countries for the automotive sector. Both the industry as well as users could benefit from a study such as this, so that these types of failures are reduced, causing less damage to all. Based in previous examples such as the ones done by Baraldi \& Kaminski (2016) and Bates et al. (2007) this work, as previously stated, aims to investigate the extent of available information, in order to analyse and compare how motor vehicle recalls are currently performed and by doing so, investigate possible trends and its resulting consequences, both in Brazil and Germany, assessing the different companies that operate in these countries, looking into potential causes for differences.

\section{Methods}

The research methodology used is basically exploratory and is divided into two major stages, the first stage being a secondary survey carried out on databases of websites of the governments of Brazil and Germany that 
compile information about the recall process and also record historical data about the recalls already carried out. The second big step basically consists of performing a descriptive statistical analysis of the data collected with the aid of a tool like Python, from which exploratory hypotheses will be derived, which will serve as proposals for new research or even as suggestions for improvements for entities that manage the recall process in Brazil.

To acquire the available data, a research is carried out in the websites of governmental entities that regulate and oversee recall actions and emails are sent to the responsible persons in each country. The Brazilian law regulating recall actions is available at (Brasil, 2012). It regulates the basic right to protection of life, health and safety against risks caused by products and services identified as harmful or dangerous. The supplier of any product or service that is found to be dangerous or harmful is obligated to communicate the fact immediately to the supervising governmental agencies, passing along data on several characteristics of the product including how many products are be affected.

The Brazilian Secretaria Nacional do Consumidor (Senacon), focuses on planning, elaborating, coordinating and executing the national politics for consumer relationships (Brasil, 2018b). It is responsible for overseeing all recall actions in the country, including motor vehicles, electronics and toys, among other categories of products.

The Senacon keeps, in a specific portal (Brasil, 2018a), all digitalized records for recall actions since 2011 to the actual date, which can be exported as a spreadsheet. This file contains data concerning the OEM responsible for the recall, a classification of the type of motor vehicle affected, a value describing if the recall was voluntary or requested and the volume of affected vehicles in this recall instance. Furthermore, the Senacon also produces reports from time to time consolidating the data.

Data regarding the Brazilian automotive industry can be obtained directly from the association of Brazilian OEMs, namely: Associação Nacional de Fabricantes dos Veículos Automotores (ANFAVEA). The ANFAVEA produces yearly reports regarding the state of the Brazilian automotive industry, which contains number of licensed vehicles in total and for each OEM as well as numbers regarding production and financial data of the industry as a whole (Associação Nacional dos Fabricantes de Veículos Automotores, 2014).

The German law regulating recall actions is the Produktsicherheitsgesetz (ProdSG) which is available at (Bundesministeriums der Justiz und für Verbraucherschutz, 2011). It states that a product may only be marketed if it does not put in risk the safety and health of the people.

The German Kraftfahrt-Bundesamt (KBA) is responsible for overseeing most matters regarding motor vehicles and especially motor vehicle recall actions in Germany, following the requirements of the ProdSG. The KBA keeps in a specific website digital records of recall actions (Kraftfahrt-Bundesamt, 2018). It does not claim to be complete nor does it allow data to be exported, showing each recall action on a different webpage.

The KBA also produces annual or biannual reports consolidating information of recall actions, whereas as of this date the latest report refers to 2013 and 2014 (Kraftfahrt-Bundesamt, 2015). It is notable that the German KBA offers much less data than its Brazilian counterpart. Moreover, at the moment this article is being written, the released data has a 4-year delay (last report regarding the years 2013 and 2014) and does not contain specifics for each OEM.

Germany also has an association of German OEMs, the Verband der Automobilindustrie (VDA). The VDA has in its website a section devoted to facts and figures of the German automotive industry, for example regarding new registrations of vehicles (Verband der Automobilindustrie, 2018).

From the described websites of governmental entities, two sets of data are available, one in the format of a report and one in the format of a spreadsheet table. Table 2 shows the subset of consolidated data present in reports from these entities. More reports are available but contain no additional relevant information and were therefore left out. The Brazilian Senacon also offers in its website the possibility to export a spreadsheet with the columns as described in Table 3.

Since data for motor vehicle recalls in Germany is only available until 2014, beginning the analysis from 2005 allows the visualization of 10 years of data for this country, with the numbers for Brazilian recalls overlapping between 2011 to 2014 and the Brazilian data going until 2017, the most recent to this date. The timeframe chosen for the analysis is thus from 2005 to 2017 where data is available.

For the analysis, the relevant data for this timeframe available in the PDF documents shown in Table 2 is first transformed into spreadsheets. The most important being number of licensed vehicles, number of recalls and total affected vehicles each year. The tool chosen to analyze the available data is Python, employing libraries specific for data analysis such as pandas, numpy, scipy and matplotlib for the visualization of data.

\section{Results}

This section shows the main results of this work, which begin with an overview of the available data, comparing the most relevant metrics in each of the two countries across the last years, such as number of recall 
events, number of recalled vehicles and number of licensed vehicles. Then a method for comparing recall rates of two different countries is developed, using the number of licensed vehicles and the number of recalled vehicles each year. Next a comparison of recall rates in different OEMs in Brazil is done, analysing the most important reason for recalls in the last years. Finally, a calculation of the probability bounds that a car that was licensed in the last 5 years in Brazil was recalled is also done.

Table 2. Consolidated data acquired in the form of reports.

\begin{tabular}{|c|c|c|c|c|}
\hline Country (department) & Year & Document name & Data found & Time horizon \\
\hline \multirow{3}{*}{ Brazil (SENACON) } & \multirow{3}{*}{2016} & \multirow{3}{*}{$\begin{array}{l}\text { Boletim Recall 2016 (Brasil, } \\
\text { 2018b) }\end{array}$} & - Total number of recalls & 2003 to 2016 \\
\hline & & & $\begin{array}{c}\text { - Total number of recalls by supplier of } \\
\text { product }\end{array}$ & 2016 \\
\hline & & & - Total number of recalls by hazard type & 2016 \\
\hline \multirow{4}{*}{$\begin{array}{l}\text { Brazil (SENACON and } \\
\text { DENATRAN) }\end{array}$} & \multirow{4}{*}{2016} & \multirow{4}{*}{$\begin{array}{l}\text { Boletim de Recall: Veículos } \\
\text { (Brasil, 2016) }\end{array}$} & - Total number of recalls & 2013 to 2015 \\
\hline & & & - Volume of affected vehicles & 2013 to 2015 \\
\hline & & & $\begin{array}{l}\text { - Percentage of vehicle recalls in } \\
\text { relation to total number of recalls }\end{array}$ & 2013 to 2015 \\
\hline & & & $\begin{array}{l}\text { - Average time between manufacturing } \\
\text { of vehicles and its recall }\end{array}$ & 2013 to 2015 \\
\hline \multirow{2}{*}{$\begin{array}{l}\text { Brazil (ANFAVEA) } \\
2018\end{array}$} & \multirow{2}{*}{2018} & $\begin{array}{l}\text { Brazilian automotive industry } \\
\text { yearbook: } 2018 \text { (Associação }\end{array}$ & $\begin{array}{l}\text { - Licensed vehicles for the associated } \\
\text { OEMs each year }\end{array}$ & 2008 to 2017 \\
\hline & & $\begin{array}{l}\text { Nacional dos Fabricantes de } \\
\text { Veículos Automotores, 2018) }\end{array}$ & - Licensed vehicles in the country & 2008 to 2017 \\
\hline \multirow{2}{*}{$\begin{array}{l}\text { Brazil (ANFAVEA) } \\
2014\end{array}$} & \multirow{2}{*}{2014} & $\begin{array}{l}\text { Brazilian automotive industry } \\
\text { yearbook: } 2014 \text { (Associação }\end{array}$ & $\begin{array}{l}\text { - Licensed vehicles for the associated } \\
\text { OEMs each year }\end{array}$ & Beginning of operations to 2013 \\
\hline & & $\begin{array}{l}\text { Nacional dos Fabricantes de } \\
\text { Veículos Automotores, 2014) }\end{array}$ & - Licensed vehicles in the country & 2004 to 2013 \\
\hline \multirow{3}{*}{ Germany (KBA) } & \multirow{3}{*}{2015} & \multirow{3}{*}{$\begin{array}{c}\text { Jahresbericht 2013/2014 } \\
\text { (Kraftfahrt-Bundesamt, 2015) }\end{array}$} & - Total number of recalls & 2009 to 2014 \\
\hline & & & - Total number of monitored recalls & 2009 to 2014 \\
\hline & & & - Volume of affected vehicles & 2009 to 2014 \\
\hline \multirow{3}{*}{ Germany (KBA) } & \multirow{3}{*}{2013} & \multirow{3}{*}{$\begin{array}{c}\text { Jahresbericht } 2012 \text { (Kraftfahrt- } \\
\text { Bundesamt, 2013) }\end{array}$} & - Total number of recalls & 1998 to 2012 \\
\hline & & & - Total number of monitored recalls & 1998 to 2012 \\
\hline & & & - Volume of affected vehicles & 2004 to 2012 \\
\hline
\end{tabular}

Table 3. Columns of exported spreadsheet data of Brazilian recall actions.

\begin{tabular}{|c|c|c|c|c|c|c|}
\hline Column & Classification & Protocol Year & Object & Defect & Volume affected & Origin of recall \\
\hline Brief explanation & $\begin{array}{c}\text { Choice of category } \\
\text { from: Automobiles, } \\
\text { Motorcycles, } \\
\text { Trucks, } \\
\text { Cyclomotors, } \\
\text { Busses and Auto } \\
\text { parts }\end{array}$ & $\begin{array}{l}\text { Choice of year } \\
\text { from } 2011 \text { to } 2018\end{array}$ & $\begin{array}{c}\text { Name of the } \\
\text { product }\end{array}$ & $\begin{array}{c}\text { Problem } \\
\text { description }\end{array}$ & $\begin{array}{c}\text { Volume of } \\
\text { products affected } \\
\text { when available }\end{array}$ & $\begin{array}{c}\text { Choice of category: } \\
\text { designated or } \\
\text { voluntary }\end{array}$ \\
\hline
\end{tabular}

These metrics and results allow a fair comparison of recalls in both countries, with what frequency they occur, which OEMs recall more vehicles and how likely is a vehicle to be recalled. The data supports the insights on how these processes could be improved, which are shown in the conclusion.

Table 3 shows how the data available for Brazil is organized. In this country, in contrast with Germany, data is available for each recall action, with the recall actions classified between automobiles, motorcycles, trucks, cyclomotors, busses and auto parts. This spreadsheet provides information on 635 recall actions in the period of 2011 to 2017.

With the data present in this it is possible to create a table with the number of recall actions for each year by category in Brazil, which is shown in Table 4. Based on this, Figure 1 and Figure 2 show graphs of the recall actions for each classification and the total number of affected products each year. It is clear in both graphs that the recalls classified as automobiles are much more relevant than all other categories, since they cause the highest 
number of recall actions and affect more products than all other categories by far. In fact, automobiles are responsible for $79.2 \%$ of all recall incidents and for $94.6 \%$ of all affected products in Brazil.

Table 4. Number of recall actions in Brazil by classification

\begin{tabular}{lcccccc}
\hline Year & Automobiles & Motorcycles & Trucks & Cyclomotors & Busses & Auto parts \\
\hline $\mathbf{2 0 1 1}$ & 34 & 15 & 1 & 3 & 2 & 0 \\
$\mathbf{2 0 1 2}$ & 35 & 16 & 2 & 2 & 2 & 1 \\
$\mathbf{2 0 1 3}$ & 58 & 9 & 3 & 0 & 0 & 2 \\
$\mathbf{2 0 1 4}$ & 74 & 10 & 4 & 0 & 0 & 1 \\
$\mathbf{2 0 1 5}$ & 89 & 23 & 2 & 0 & 0 & 0 \\
$\mathbf{2 0 1 6}$ & 105 & 11 & 2 & 4 & 0 & 0 \\
$\mathbf{2 0 1 7}$ & 108 & 11 & 6 & 0 & 0 & 0 \\
\hline
\end{tabular}

Source: Brasil (2018b).

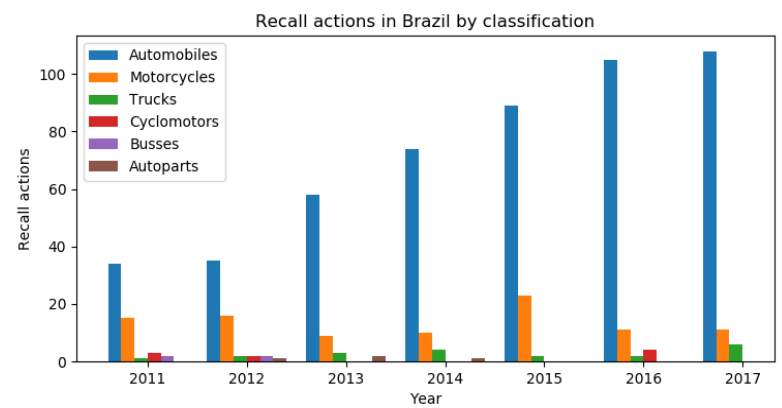

Figure 1. Recall actions in Brazil by classification.

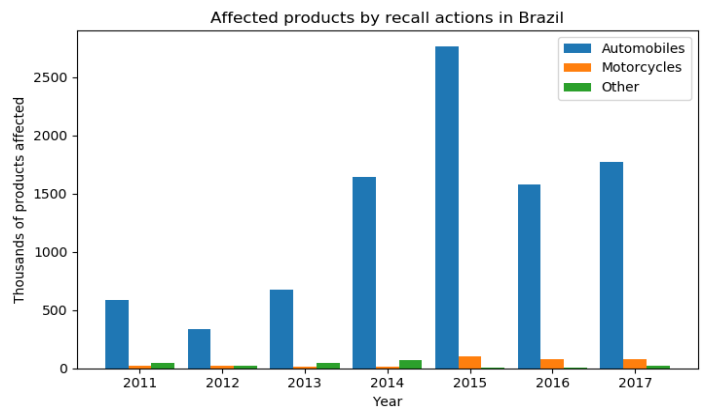

Figure 2. Number of affected products in Brazil by classification.

Superposing the graphs for recall actions and for products affected shows how they are interrelated in each country. Figure 3 and Figure 4 show the number of recall incidents and the number of affected vehicles in a single visualization for Brazil and Germany respectively.

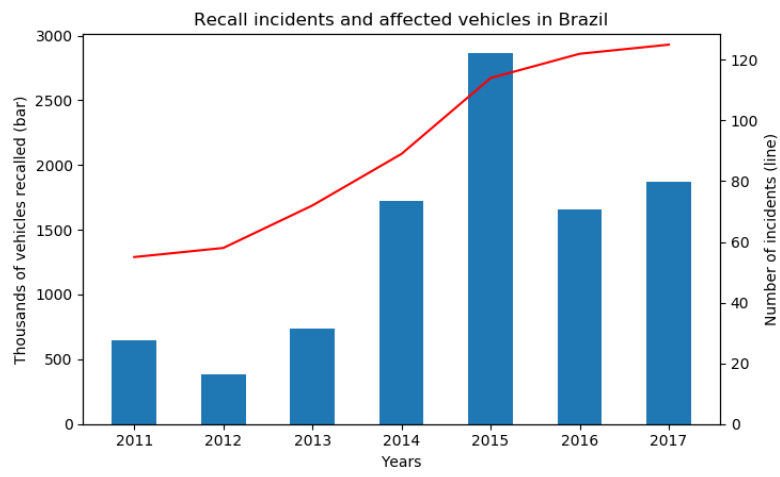

Figure 3. Recall incidents and affected vehicles in Brazil. 


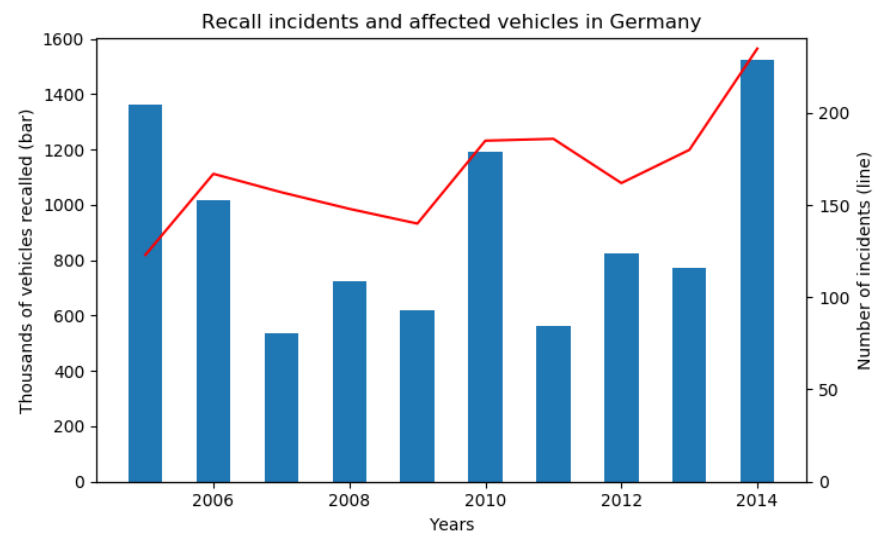

Figure 4. Recall incidents and affected vehicles in Germany.

The visualization of Figure 3 allows the conclusion that as the number of recall incidents grow, so does the number of affected products in a similar slope. It also shows that in some years, such as 2015 , the number of affected vehicles was much higher than expected. This happened because, in this year, some very important recalls dominated the dataset with the most affected products of all, all of them related to an airbag manufacturer based in the Asia-Pacific region. This recall affected millions of cars worldwide, with brands involved in this recall including OEMs based in Asia-Pacific, America and Europe (Tabuchi \& Jensen, 2014).

For Germany, the same conclusions cannot be drawn. In Figure 4, the number of recall actions tends to grow, whereas the number of vehicles recalled oscillates and does not allow the conclusion that it is growing. A look at the $y$ axis on the right of both figures also shows that the number of recall incidents in Germany is much higher than the one in Brazil.

A direct comparison of the number of recall incidents between both countries is made possible with Figure 5. This figure shows how the amount of recall actions is growing in both countries. For each of the countries a trend line is plotted with a linear fit of the data. The values for $R^{2}$ and a visual analysis of the data indicate that they are not linearly growing, nonetheless the linear fit shows how recall actions are growing in both countries and that recalls in Brazil are growing at a faster pace than in Germany.

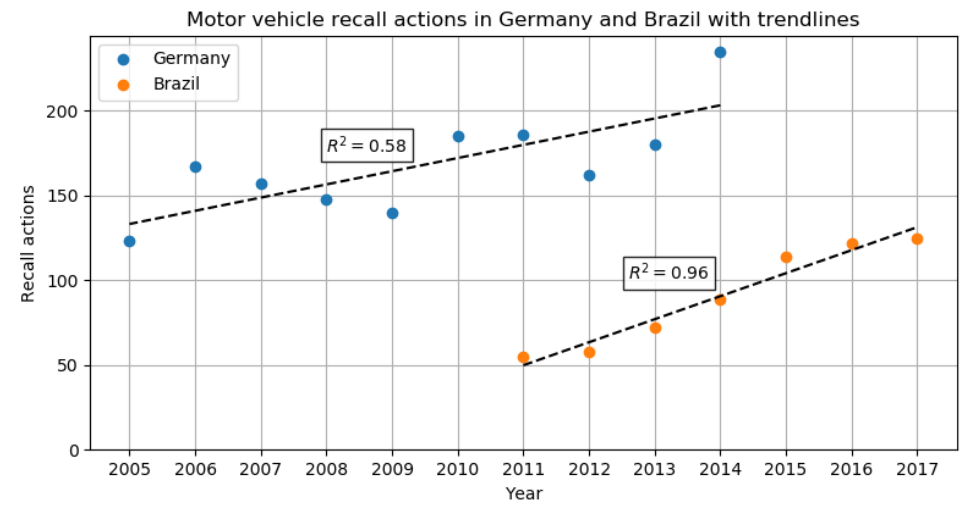

Figure 5. Motor vehicle recall actions in Germany and Brazil with trendlines.

A possible explanation for this behaviour is that Brazil still has a lot to learn in terms of regulation and law enforcement with the German authorities. In partnership with the University of Brasília (UnB), the Denatran and Senacon have analysed between 2011 and 2016 only a total of 42 cases of possible safety hazards in motor vehicles (Brasil, 2016), whereas the German KBA oversees around 100 recall actions every year (KraftfahrtBundesamt, 2015).

After the comparison of the number of recall actions a comparison of the number of affected products in both countries is pursued. Comparing these volumes directly would make little sense since the number of licensed vehicles in these countries are different. To make the comparison of these volumes it is first necessary to analyse the number of licensed vehicles in each country. The number of licensed vehicles in Brazil and in Germany can be seen in Figure 6. This figure shows how the number of licensed vehicles every year in Germany seems to have achieved somewhat stable values between 3million and 4 million vehicles per year. The Brazilian market on the 
other hand has seen significant growth from 2005 to 2012, where it started to decrease, reaching a minimum in 2016 (almost as low as in 2006) and started growing again in 2017.

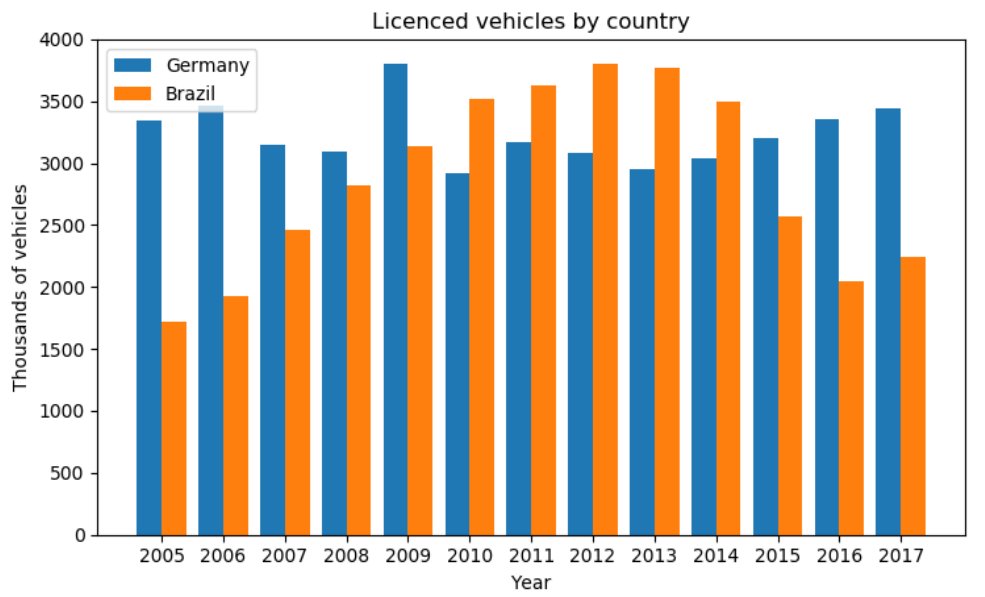

Figure 6. Licensed vehicles by country.

These newly licensed vehicles may be the object of a recall within the next years. Bates et al. (2007) has studied how long since the build year a vehicle is recalled in the United Kingdom. According to his work, recalls occur more frequently in the first 4 year safter a car was built, with the distribution being: $21 \%$ in the build year, $33 \%$ after 1 year, $25 \%$ after 2 years, $12 \%$ after 3 years and $8 \%$ after 4 years, and only $0.9 \%$ of the recalls in year 5 or more after build year. The first 5 years are responsible for $99 \%$ of all recalled vehicles.

In Brazil, SENACON and DENATRAN (Brasil, 2016) corroborate these findings by stating that most companies in Brazil perform their recalls on average on cars less than 5 years after the build year. German reports do not provide any data on whether recalls happen close to the vehicle's build year.

To compare the number of recalled motor vehicles in both countries simply dividing the number of recalled vehicles in a year by the number of licensed vehicles in the same year (as done by Bates et al., 2007) is not realistic, since vehicles that are being recalled in a specific year relate mostly to vehicles licensed up to 5 years before. To take this into consideration, the total number of recalls can be divided by a weighted average of the number of licensed vehicles in the last 5 years (including the current year). The weights are assumed based on the trend of recalls after build year found in the UK by Bates et al. (2007), namely $20 \%$ in current year, $35 \%$ after 1 year, $25 \%$ after 2 years, $12 \%$ after 3 years and $8 \%$ after 4 years. Equation 1 shows this calculation for the year $\mathrm{n}$, yielding the metric defined as $V_{n}$,

$V_{n}=\frac{R_{n}}{L_{n} * 0.20+L_{n-1} * 0.35+L_{n-2} * 0.25+L_{n-3} * 0.12+L_{n-4} * 0.08}$

where $R_{n}$ is the number of recalled vehicles in year $n, L_{n}$ is the number of licensed vehicles and the weights for the first five years were rounded and normalized so that their sum is unitary.

This metric is important because it allows a direct comparison of the findings in different countries, taking into consideration that in each country different amounts of vehicles are licensed each year. It also allows each country to evaluate how its recalls evolve each year, possibly allowing the creation of public policies that target these values.

A comparison for the values obtained for the number of recalled motor vehicles divided by the 5-year weighted average of licensed vehicles can be seen in Figure 7. It is notable in this figure that the values of Brazil and Germany are closely related to each other between 2011 and 2014. The trends for Brazil are increasing after this, with a very high peak in 2015 that can be explained, as stated before, by airbag recalls. The values used for calculating these graphs are also available as tables. Table 5 and Table 6 show the values for obtained for recall actions in Brazil and in Germany respectively. 


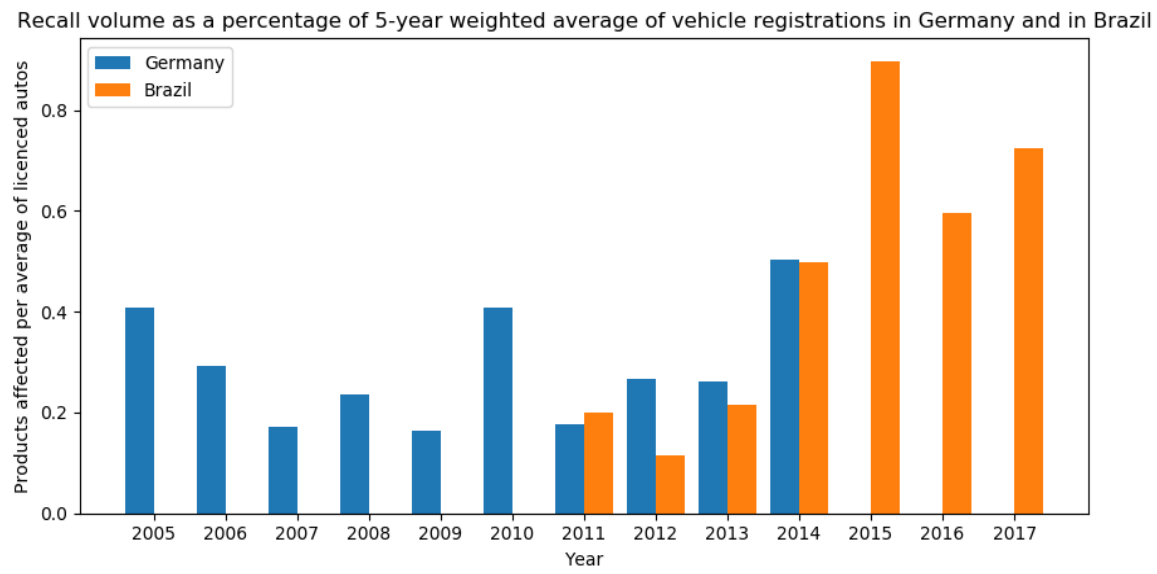

Figure 7. Recalls as a percentage of the weighted average of vehicle registrations in Germany and in Brazil.

Table 5. Values for recall actions and licensed vehicles in Brazil.

\begin{tabular}{ccccc}
\hline Years & Licensed vehicles & $\begin{array}{c}\text { Motor vehicle recall } \\
\text { incidents }\end{array}$ & $\begin{array}{c}\text { Motor vehicle } \\
\text { products affected }\end{array}$ & $\begin{array}{c}\text { Products affected over weighted } \\
\text { average }\end{array}$ \\
\hline 2011 & 3633248 & 55 & 645963 & 0.20 \\
2012 & 3802071 & 58 & 380582 & 0.11 \\
2013 & 3767370 & 72 & 735952 & 0.21 \\
2014 & 3498012 & 89 & 1723743 & 0.50 \\
2015 & 2568976 & 114 & 2868263 & 0.90 \\
2016 & 2050317 & 122 & 1659202 & 0.59 \\
2017 & 2239682 & 125 & 1871846 & 0.72 \\
\hline
\end{tabular}

Source: Associação Nacional dos Fabricantes de Veículos Automotores (2018) and Brasil (2018b).

Table 6. Values for recall actions and licensed vehicles in Germany.

\begin{tabular}{ccccc}
\hline Years & Licensed vehicles & $\begin{array}{c}\text { Motor vehicle recall } \\
\text { incidents }\end{array}$ & $\begin{array}{c}\text { Motor vehicle } \\
\text { products affected }\end{array}$ & $\begin{array}{c}\text { Products affected over weighted } \\
\text { average }\end{array}$ \\
\hline 2005 & 3342122 & 123 & 1362630 & 0.42 \\
2006 & 3467961 & 167 & 1018000 & 0.31 \\
2007 & 3148163 & 157 & 536000 & 0.16 \\
2008 & 3090040 & 148 & 725937 & 0.22 \\
2009 & 3807175 & 140 & 618809 & 0.19 \\
2010 & 2916260 & 185 & 1191094 & 0.36 \\
2011 & 3173634 & 186 & 563414 & 0.17 \\
2012 & 3082504 & 162 & 824349 & 0.26 \\
2013 & 2952431 & 180 & 770262 & 0.25 \\
2014 & 3036773 & 235 & 1526280 & 0.50 \\
\hline
\end{tabular}

Source: Kraftfahrt-Bundesamt (2013, 2015) and Verband der Automobilindustrie (2018).

Considering that data is available for each recall action in Brazil, a deeper analysis can be made for the years of 2011 to 2017 in this country. Each of the OEMs associated with Associação Nacional dos Fabricantes de Veículos Automotores (2018) is taken into consideration and Table 7 is created using data from the spreadsheet and from the reports, based on the procedure done by Bates et al. (2007) and shows the OEMs in order of descending number of affected products over the number of licensed vehicles. The names of the OEMs were suppressed and changed for indicative letters, followed by the region of its headquarters in parenthesis. 
Table 7. Recalls in Brazil from 2011 to 2017 grouped by affected OEM and ranked by the number of vehicles affected in recall actions divided by the total licensed vehicles.

\begin{tabular}{ccccccc}
\hline OEM (region of headquarters) & Recalls & Affected & Max Affected at once & Licensed & Affected over licensed \\
\hline A (Asia-Pacific) & 23 & 2107203 & 34530 & 912081 & 2.31 \\
B (Asia-Pacific) & 34 & 1827134 & 384596 & 1132832 & 3.61 \\
C (Asia-Pacific) & 13 & 316494 & 255 & 361474 & 0.88 \\
D (Asia-Pacific) & 14 & 396243 & 193578 & 523217 & 0.76 \\
E (Europe) & 27 & 382908 & 34367 & 698389 & 0.55 \\
F (America) & 28 & 863428 & 20020 & 2042584 & 0.42 \\
G (America) & 37 & 1405069 & 159696 & 3631743 & 0.39 \\
H (Europe) & 11 & 16927 & 5570 & 51543 & 102312 & 0.33 \\
I (Europe) & 31 & 26935 & 5159 & 4289934 & 0.26 \\
J (Europe) & 77 & 875521 & 9958 & 61901 & 0.20 \\
L (Europe) & 31 & 11026 & 3324 & 870250 & 0.18 \\
M (Asia-Pacific) & 3 & 152020 & 139159 & 3587433 & 0.18 \\
N (Europe) & 26 & 547148 & 170443 & 14401 & 399223 & 0.15 \\
O (Europe) & 44 & 44419 & 119694 & 1407932 & 0.11 \\
P (Europe) & 10 & 5394 & 1060 & 0.09 \\
Q (Europe) & 16 & 0.05 & \\
\hline
\end{tabular}

Source: Associação Nacional dos Fabricantes de Veículos Automotores (2018) and Brasil (2018b).

This table allows a comparison of the OEMs regarding the ratio of products affected by recalls over the total licensed vehicles in the period, thus allowing a notion of the odds of a car of that specific OEM to be recalled. It is important to note that values above 1 are possible, given that the number of licensed vehicles is decreasing and that the same car can be affected by two different recall actions.

In this table it is possible to note a very broad range of vehicles affected over the number of licensed automobiles, ranging from 0.05 to 2.31. It is also possible to note the predominance of Asian-Pacific OEMs within the highest values and the predominance of European OEMs among the smallest, with 4 out of the 10 smallest numbers being German OEMs.

As stated before, during 2015 and 2016 several recall actions occurred because of safety problems in the airbags manufactured by a company based in the Asia-Pacific region. These recalls affected several brands and a very high volume of automobiles. From the available dataset, a total of 92 recall actions were caused by problems in airbags. Airbags were responsible for $19 \%$ of the recall actions in the period and for $36.8 \%$ of the affected vehicles. If the recalls caused by airbags are removed from the dataset, a very different table and ranking is obtained.

Table 8 shows the same values only for recalls that are not caused by defective airbags. The changes in values and in the order are easily noted. The range of affected products over licensed vehicles drops to 0.05 to 0.84 . The order of OEMs also changes drastically. The OEM indicated by letter "B" for instance drops 5 positions and the one indicated by " $\mathrm{D}$ " drops 10 positions. Those brands were clearly very affected by airbag recalls.

Furthermore, it is possible to calculate a range of the probability that a single car was a part of a recall action between 2011 and 2017 in Brazil if it was licensed in these years. According to Bates et al. (2007) a maximum and a minimum value can be calculated using the available data. For the minimum range, the assumption that all vehicles from a specific brand are a part of this brands largest recall action by volume of affected vehicles. The probability is then given by:

$P_{\text {lower }}=\frac{\sum_{i=1}^{n} \operatorname{Max}_{j=1}^{m}\left(V_{i j}\right)}{\sum_{i=1}^{n} R_{i}}$

Where $V_{i j}$ is the volume of affected products in the recall incident $i$ for vehicle manufacturer $\mathrm{j}$ and $R_{i}$ is the overall registrations for the period for a manufacturer.

Similarly, the upper bound of the propensity of recall for a vehicle can be calculated assuming that no car is affected twice by different recall actions. The probability is then 
$P_{\text {upper }}=\frac{\sum_{i=1}^{n} \sum_{j=1}^{m} V_{i j}}{\sum_{i=1}^{n} R_{i}}$

Where $V_{i j}$ and $R_{i}$ are the same as described before.

Using Equations 2 and 3 it is possible to find that $P_{\text {lower }}=5.9 \%$ and $P_{\text {upper }}=45.9 \%$. The probability that a vehicle is recalled if it was registered between 2011 and 2017 is somewhere between $5.9 \%$ and $45.9 \%$.

Table 8. Recalls not regarding airbags in Brazil from 2011 to 2017 grouped by affected OEM and ranked by the number of vehicles affected in recall actions divided by the total licensed vehicles.

\begin{tabular}{cccccc}
\hline OEM & Recalls & Affected & Max Affected at once & Licensed & Affected over licensed \\
\hline A (Asia-Pacific) & 17 & 767590 & 555 & 912081 & 0.84 \\
C (Asia-Pacific) & 9 & 254578 & 255 & 361474 & 0.70 \\
E (Europe) & 27 & 382908 & 34367 & 698389 & 0.55 \\
F (America) & 24 & 825913 & 20020 & 2042584 & 0.40 \\
G (America) & 33 & 1386825 & 159696 & 3631743 & 0.38 \\
B (Asia-Pacific) & 19 & 307936 & 80212 & 1132832 & 0.27 \\
H (Europe) & 8 & 10553 & 5570 & 51543 & 0.21 \\
J (Europe) & 57 & 829806 & 9958 & 4289934 & 0.19 \\
I (Europe) & 23 & 18639 & 5159 & 102312 & 0.18 \\
L (Europe) & 30 & 11025 & 3324 & 61901 & 0.18 \\
M (Asia-Pacific) & 3 & 152020 & 139159 & 870250 & 0.18 \\
N (Europe) & 21 & 489971 & 170443 & 3587433 & 0.14 \\
D (Asia-Pacific) & 8 & 63709 & 29143 & 523217 & 0.12 \\
O (Europe) & 37 & 40805 & 14401 & 399223 & 0.10 \\
P (Europe) & 9 & 115874 & 24814 & 1407932 & 0.08 \\
Q (Europe) & 12 & 5133 & 1960 & 103579 & 0.05 \\
\hline
\end{tabular}

Source: Associação Nacional dos Fabricantes de Veículos Automotores (2018) and Brasil (2018b).

\section{Conclusions}

To reach the goal of this research, a theoretical reference is first laid out. The different approaches to the PDP define possible subdivisions and methods for solving the product development problem. Most of the approaches have a clear division of phases between the development of the product and the development of the production process. Most approaches also assume that this development can or should be iterative, refining the characteristics of the product and process, correcting possible problems throughout the development.

These references show that the later a change in the product's specifications is made, the higher the costs caused by this change. The latest stage where a change is possible is during product use, where product recalls will cause direct costs for the recall itself as well as costs for the brand image of the OEM and possible costs of changing faulty production process. The references found regarding recall actions showed how the governmental surveillance actions influence not only government-initiated recall actions but also voluntary recalls.

The different governmental entities regulating recall actions in Brazil and in Germany are then investigated. The main difference found is that the German KBA is responsible for matters regarding motor vehicles and only oversees recalls related to motor vehicles, whereas the Brazilian Senacon is responsible for consumers' safety on all categories of products. The German KBA makes very little data regarding the overall yearly recall actions available in the form of annual or biannual reports that lag 4 years as of the writing of this work, whereas the Brazilian Senacon makes data available in the form of a spreadsheet with information on each individual recall action.

The data available shows how the number of recall actions is much higher in Germany. The values are increasing in both countries, with Brazil having a higher slope and possibly reaching the number of recall actions in Germany if both countries maintain their trends. A possible cause for this is that the Brazilian government is increasing its surveillance by analyzing defective products where a recall could be required.

Data also shows how the number of recall actions and the volume of affected motor vehicles in Brazil is mainly driven by automobile recalls and the same is assumed as true for German motor vehicles. This showed 
that the introduction of the variable for the number of licensed vehicles each year is beneficial. The annual value of licensed vehicles shows how Brazil, after years of successfully increasing the number of licensed automobiles suffered from a decrease in this number in the years of 2012 to 2016 , caused by an economic crisis.

To compare both countries, a metric is created, based on the weighted average of licensed automobiles in the last 5 years, weighted by the percentage of vehicles recalled according to its build year. This metric allows a comparison of the values in each country, taking into consideration possible fluctuations in the number of licensed vehicles each year. This metric also allows each country to evaluate how its recalls evolve each year, possibly allowing the creation of public policies that target these values.

An analysis of the number of affected vehicles per weighted average of licensed automobiles allowed a comparison of both countries. The calculated values seem very similar for the years when data is available for both countries (2011 to 2014), but the trends seem to vary largely for Brazil in the next years (2015 to 2017).

The data found corroborates with the theory initiated by Rupp \& Taylor (2002) because it shows that Brazil, which does less surveillance, has a smaller number of recall incidents than Germany, which does more surveillance, but not a significantly smaller total of affected vehicles, since, according to them, the governmental surveillance tends to affect recalls with a smaller number of affected vehicles.

The Brazilian data allowed a closer look into each OEM present in the country and being part of ANFAVEA. A ranking of these companies was created based on the number of affected vehicles by recall actions divided by the number of licensed cars for this OEM during the entire available timeframe (2011 to 2017). The case of airbag recalls showed how a failure in a supplier can lead to much higher recall rates over several companies across the world.

From the presented conclusions, including the differences in governmental agencies that regulate recall actions and the created ranking for OEMs, the following questions are drawn:

(1) Does the difference in scope of the governmental entities changes how recalls are dealt with? What differences can be seen between countries that have governmental agencies that only regulate motor vehicles and governmental agencies that regulate all products recall actions?

(2) What does the OEMs ranking based on the number of recalled vehicles divided by the number of licensed automobiles represent?

(3) Where in the PDP did a failure occur that led to these recalls?

Further work in this subject can attempt to answer the questions 1 to 3 that are laid out in this conclusion. A comparison of other countries, investigating how their governmental entities are organized and how recall actions are performed could theorize an answer to the question number 1.

Question 2 has a more theoretical nature. The main causes for a company being higher on the ranking (having a higher number of recalled vehicles divided by the number of licensed automobiles) could be related to a lower PDP quality, higher safety standards or even a higher compliance with the law. This question could be answered with a qualitative research between the different OEMs, looking at the internal causes of recalls.

Finally, question 3 stands as one of the most important for OEMs and for the government. Only after understanding where in the PDP a failure occurred, can this failure (and its severe consequences) be avoided in the future. A possible answer could be found based on a classification of the problems that led to a recall, for example dividing the existing dataset into recalls caused by product design failure or by process failures. This would allow companies to have at least an overview of where the problem originated and allowing it to make improvements in these areas, possibly reducing the number of vehicles recalled in the future.

As a future work, it would be interesting to analyse the different requirements and laws in cases of recall between different geographic regions. This research was able to show, already, a possible correlation between automotive recalls and their disclosure and the impacts caused on the relationship between society and the manufacturer, considering the different regions.

Another opportunity would be a research on the differentiation and interpretation of data available for different regions of interest, using machine learning algorithms to develop analyzes on the health of members of civil society and the economy of the regions studied. For that, three categories of algorithms would be used (grouping, classification and regression) to finally develop an analysis of the data using artificial neural networks in the three categories of algorithms.

\section{References}

Asimow, M. (1962). Introduction to design. Englewood Cliffs, NJ: Prentice-Hall.

Associação Nacional dos Fabricantes de Veículos Automotores - ANFAVEA. (2014). Brazilian automotive industry yearbook: 2014. São Paulo. Retrieved in 2018, November 5, from http://www.virapagina.com.br

Associação Nacional dos Fabricantes de Veículos Automotores - ANFAVEA. (2018). Brazilian automotive industry yearbook: 2018. São Paulo. Retrieved in 2018, November 5, from http://www.virapagina.com.br 
Ball, G. P., Shah, R., \& Donohue, K. (2018a). The decision to recall: a behavioral investigation in the medical device industry. Journal of Operations Management, 62, 1-15.

Ball, G. P., Shah, R., \& Wowak, K. D. (2018b). Product competition, managerial discretion, and manufacturing recalls in the U.S. pharmaceutical industry. Journal of Operations Management, 58-59(1), 59-72.

Baraldi, E. C., \& Kaminski, P. C. (2016). A study on the causes of recall in automotive vehicles marketed in Brazil (SAE Technical Paper). SAE International.

Baraldi, E. C., \& Kaminski, P. C. (2018). Reference model for the implementation of new assembly processes in the automotive sector. Cogent Engineering, 5(1), 1482984.

Bates, H., Holweg, M., Lewis, M., \& Oliver, N. (2007). Motor vehicle recalls: trends, patterns and emerging issues. Omega, 35(2), 202-210.

Bernon, M., Bastl, M., Zhang, W., \& Johnson, M. (2018). Product recalls: the effects of industry, recall strategy and hazard, on shareholder wealth. International Journal of Business Science and Applied Management, 13, 1.

Brasil. Ministério da Justiça (2012, March 16). Portaria n ${ }^{\circ} 487$, de 15 de março de 2012. Diário Oficial [da] República Federativa do Brasil, Brasília. Retrieved in 2018, September 30, from http://www.justica.gov.br

Brasil. Ministério da Justiça. Secretaria Nacional do Consumidor - SENACON. (2018a). Consumidor. Retrieved in 2018 , September 30, from http://justica.gov.br

Brasil. Secretaria Nacional do Consumidor - SENACON. (2018b). Recall. Retrieved in 2018, September 30, from http://portal.mj.gov.br

Brasil. Secretaria Nacional do Consumidor - SENACON. Departamento Nacional de Trânsito - DENATRAN. (2016). Boletim de recall: veículos. Retrieved in 2018, September 30, from http://www.justica.gov.br

Bundesministeriums der Justiz und für Verbraucherschutz - BMJV. 2011). Gesetz über die Bereitstellung von Produkten auf dem Markt: (Produktsicherheitsgesetz - ProdSG) [Act on the provision of products on the market (Product Safety Act - ProdSG)]. Retrieved in 2018, September 30, from https://www.gesetze-im-internet.de

Cavazos, D. E., Rutherford, M., \& Berman, S. L. (2018). Assessing the effect of government surveillance on firm supererogation: the case of the U.S. automobile industry. Business Ethics, 27(2), 156-163.

Clark, K. B., \& Fujimoto, T. (1991). Product development performance: strategy, organization, and management in the world auto industry. Brighton, MA: Harvard Business School Press.

Clark, K. B., \& Wheelwright, S. C. (1993). Managing new product and process development: text and cases. New York: The Free Press.

Cooper, R. G. (1990). Stage-gate systems: a new tool for managing new products. Business Horizons, 33(3), $44-54$.

Cooper, R., Edgett, S., \& Kleinschmidt, E. (2001). Portfolio management for new product development: results of an industry practices study. $R \& D$ Management, 31(4), 361-380.

Dieter, G. E., \& Schmidt, L. C. (2009). Engineering design (4th ed.). Boston: McGraw-Hill Higher Education.

Evans, J. H. (1959). Basic design concepts. Naval Engineers Journal, 71(4), 671-678.

Giakatis, G., \& Rooney, E. M. (2000). The use of quality costing to trigger process improvement in an automotive company. Total Quality Management \& Business Excellence, 11(2), 155-170.

Hora, M., Bapuji, H., \& Roth, A. V. (2011). Safety hazard and time to recall: the role of recall strategy, product defect type, and supply chain player in the U.S. toy industry. Journal of Operations Management, 29(7-8), 766-777.

International Organization of Motor Vehicle Manufacturers - OICA. (2018).World vehicles in use - all vehicles. Retrieved in 2018, September 30, from http://www.oica.net

Kraftfahrt-Bundesamt - KBA. (2013). Jahresbericht 2012 [Annual report 2012]. Retrieved in 2018, September 30, from https://www.kba.de

Kraftfahrt-Bundesamt - KBA. (2015). Jahresbericht 2013/2014 [Annual report 2013/2014]. Retrieved in 2018, September 30, from https://www.kba.de

Kraftfahrt-Bundesamt - KBA. (2018). Rückrufdatenbank. Retrieved in 2018, September 30, from https://www.kba-online.de

Krishnan, V., \& Ulrich, K. T. (2001). Product development decisions: a review of the literature. Management Science, 47(1), 1-21.

Lin, L.-H., \& Lu, I.-Y. (2006). Product quality as a determinant of product innovation: an empirical analysis of the global automotive industry. Total Quality Management \& Business Excellence, 17(2), 141-147.

Rupp, N. G., \& Taylor, C. R. (2002). Who initiates recalls and who cares? Evidence from the automobile industry. The Journal of Industrial Economics, 50(2), 123-149.

Silva, G. C., \& Kaminski, P. C. (2016). Selection of virtual and physical prototypes in the product development process. International Journal of Advanced Manufacturing Technology, 84, 1513-1530.

Silva, G. C., \& Kaminski, P. C. (2017). Proposal of framework to managing the automotive product development process. Cogent Engineering, 4, 1.

Suh, N. P. (2001). Axiomatic design: advances and applications. New York: Oxford University Press.

Tabuchi, H., \& Jensen, C. (2014, June 23). Now the air bags are faulty, too. The New York Times. Retrieved in 2018, November 5, from https://www.nytimes.com

Ulrich, K. T., \& Eppinger, S. D. (2012). Product design and development (5th ed.). New York: McGraw-Hill. 
VDI-Fachbereich Produktentwicklung und Mechatronik. (1993). Systematic approach to the design of technical systems and products. Düsseldorf: VDI-GPP.

Verband der Automobilindustrie - VDA. (2018). New registrations. Berlin. Retrieved in 2018, November 5, from https://www.vda.de

Weber, J. (2009). Automotive development processes. Berlin: Springer.

Wynn, D. C., \& Clarkson, P. J. (2018). Process models in design and development. Research in Engineering Design, 29(2), 161202. 